\title{
Chemokines and chemokine receptors expression in the lesions of patients with American cutaneous leishmaniasis
}

\author{
Nilka Luisa Díaz/ ${ }^{+}$, Olga Zerpa, Félix Jacobo Tapia \\ Instituto de Biomedicina, Universidad Central de Venezuela, Caracas, Venezuela
}

\begin{abstract}
American cutaneous leishmaniasis (ACL) presents distinct active clinical forms with different grades of severity, known as localised (LCL), intermediate (ICL) and diffuse (DCL) cutaneous leishmaniasis. LCL and DCL are associated with a polarised T-helper (Th)1 and Th2 immune response, respectively, whereas ICL, or chronic cutaneous leishmaniasis, is associated with an exacerbated immune response and a mixed cytokine expression profile. Chemokines and chemokine receptors are involved in cellular migration and are critical in the inflammatory response. Therefore, we evaluated the expression of the chemokines CXCL10, CCL4, CCL8, CCL11 and CXCL8 and the chemokine receptors CCR3, CXCR3, CCR5 and CCR7 in the lesions of patients with different clinical forms of ACL using immunohistochemistry. LCL patients exhibited a high density of CXCL10+, CCL4+ and CCL8+ cells, indicating an important role for these chemokines in the local Th1 immune response and the migration of CXCR3+ cells. LCL patients showed a higher density of CCR7+ cells than ICL or DCL patients, suggesting major dendritic cell (DC) migration to lymph nodes. Furthermore, DCL was associated with low expression levels of Th1-associated chemokines and CCL11+ epidermal DCs, which contribute to the recruitment of CCR3+ cells. Our findings also suggest an important role for epidermal cells in the induction of skin immune responses through the production of chemokines, such as CXCL10, by keratinocytes.
\end{abstract}

Key words: chemokine - chemokine receptor - cutaneous leishmaniasis

In the New World, cutaneous leishmaniasis presents in forms with different clinical, histological and immune characteristics and differing grades of severity (Convit et al. 1993). The most common clinical form is localised cutaneous leishmaniasis (LCL), in which lesions usually heal spontaneously and predominantly exhibit a Thelper (Th)1 immune response associated with a delayed hypersensitivity reaction. Some infected individuals develop diffuse cutaneous leishmaniasis (DCL), which is characterised by multiple non-healing lesions and a predominant Th2 immune response associated with the production of non-protective antibodies (Caceres-Dittmar et al. 1993, Convit et al. 1993). Chronic cutaneous leishmaniasis, also called intermediate cutaneous leishmaniasis (ICL), is a persistent form that presents with extensive cutaneous lesions containing plaques and ulcers and is characterised by an exacerbated cell-mediated immune response that forms a granuloma containing many activated $T$ cells and produces a variety of cytokines (Caceres-Dittmar et al. 1993, Diaz et al. 2002).

The regulation of cellular migration from lymphoid to peripheral tissues plays an important role in the immune response and chemokines and chemokine receptors are critical to the molecular mechanisms driving in this process. The recruitment of naïve and memory

doi: 10.1590/0074-0276108042013008

Financial support: CDCH-UCV (PG-09-74292008/1)

+Corresponding author: nilkadiaz@gmail.com

Received 19 November 2012

Accepted 27 March 2013
$\mathrm{T}$ cells to peripheral tissue is mediated by a combination of adhesion molecules and chemokine receptors (Laudanna et al. 2002). It is also known that cytokines are directly involved in chemokine production and may precede the expression of chemokines (Ohmori et al. 1993). In fact, interleukin (IL)-12 is required for the induction of Th1-related chemokines such as XCL1 (also known as lymphotactin), CXCL10 [induced protein-10 (IP-10)] and CCL2 [monocyte chemoattractant protein (MCP)1] (Zaph \& Scott 2003) and interferon (IFN)- $\gamma$ selectively induces CXCL10 and CXCL9 (monokine induced by IFN- $\gamma$ ) (Farber 1997). Other chemokines, such as CXCL5 (RANTES) and CCL11 (eotaxin), have been associated with a Th2 response. Although chemokine receptors are not exclusively expressed on specific $\mathrm{T}$ cell subsets (Kim et al. 2001), CXCR3 appears to be expressed by most Th1 cells, whereas CCR3 is expressed primarily by Th2 cells (Bonecchi et al. 1998, Sebastiani et al. 2001).

The role of chemokines in Leishmania infection has been exhaustively studied and these findings indicate that chemokines and chemokine receptors play a crucial role in determining the outcome of the disease (Teixeira et al. 2006).

During early Leishmania infection in mice, the inflammatory infiltrate is composed of polymorphonuclear cells (PMNs) and macrophages (Silva et al. 2005, Peters et al. 2008). Humans PMNs containing Leishmania parasites produce CXCL8 (IL-8) and CCL4 [macrophage inflammatory protein (MIP)1 $\beta$ ], which are essential for recruiting macrophages and PMNs to the site of infection (van Zandbergen et al. 2004). Adaptive immunity is triggered by dendritic cells (DCs) in the skin that internalise Leishmania parasite antigens and transporting them from 
the skin to the draining lymph node for antigen presentation to naïve $\mathrm{T}$ cells. This migratory ability depends on the expression of CCR7, the receptor for CCL21 that is expressed in lymphoid tissues (Förster et al. 1999).

Despite the numerous studies describing chemokine participation in the immune response to Leishmania, very little is known about the chemokine and chemokine receptor expression patterns in human cutaneous leishmaniasis. Ritter et al. (1996) found that CCL2 and CCL3 (MIP1 $\alpha$ ) appear to be responsible for macrophage activation in skin lesions. Similarly, LCL patients infected with Leishmania mexicana exhibited high CCL2, CXCL9 and CXCL10 expression levels that were associated with a concentrated dermal infiltrate comprising macrophages and large numbers of CD4-positive $\mathrm{T}$ cells. In contrast, higher levels of CCL3 and lower levels of CXCL10 expression were present in non-healing DCL lesions, which were characterised by a more diffuse infiltrate with fewer CD4-positive T cells (Ritter \& Körner 2002). Recently, high expression of CXCR3 has been observed in the early stages of LCL lesion, whereas a higher expression level of CCL7 is typically observed in DCL lesions, suggesting that different types of cells are recruited to the site of infection for different clinical forms (Campanelli et al. 2010).

In this study, we evaluated the local production of chemokines related to Th1/Th2 responses, including CXCL10, CCL4, CCL8, CCL11 and CXCL8, as well as the expression of the receptors CCR3, CXCR3, CCR5 and CCR7 in the lesions of patients with different clinical forms of American cutaneous leishmaniasis (ACL) using immunohistochemistry. Patients exhibited different chemokine expression patterns related to the type of adaptive response that was observed. CXCR3-positive lymphocyte recruitment was increased in LCL and ICL patients, whereas DCL and ICL patients showed increased expression of CCL11 in epidermal DCs.

\section{PATIENTS, MATERIALS AND METHODS}

Patients - This study included patients with LCL (n $=20)$, ICL $(n=5)$ and DCL $(n=10)$ who were treated at the Institute of Biomedicine, Caracas, Venezuela. Before starting the study, the project was approved by the Ethical Committee of the Institute of Biomedicine, which granted the corresponding certification. Patients voluntarily participated in this study after being informed in detail about the research project and signing the informed consent form, according to the declaration of Helsinki issued by the World Medical Association (Williams 2008).

Patients were diagnosed using established clinical, epidemiological, histopathological and parasitological criteria (Convit et al. 1993). LCL patients with one or two ulcerated lesions were not receiving treatment at the time of the study. ICL patients were identified by the prolonged natural history of their disease and the presence of single or multiple lesions with verrucous, sarcoidal or vegetative development and by the presence of plaques with numerous ulcers and an overall poor response to treatment. DCL patients presented with multiple lesions disseminated throughout the body, with one- 40 years of parasitic evolution and several relapses after treatment with pentavalent antimonials. Parasitological confirmation of the clinical diagnosis was based on demonstration of Leishmania amastigotes in Giemsa or haematoxylineosin (H\&E) staining of smears from biopsies.

Skin biopsies were obtained from all subjects after they signed the informed consent form. The specimens were embedded in Cryomatrix ${ }^{\mathrm{TM}}$ resin (Shandon Pittsburgh, USA), snap-frozen and stored in liquid nitrogen until examination. Frozen sections $(5 \mu \mathrm{m})$ were cut at $-30^{\circ} \mathrm{C}$ with a cryostat (Shandon, Pittsburgh, USA) and airdried overnight prior to the immunostaining procedure.

Antibodies - All antibodies used were diluted in phosphate-buffered saline (PBS), $\mathrm{pH}$ 7.2. For chemokine characterisation of frozen sections, affinity-purified goat polyclonal antibodies directed to the following human chemokines were used: CXCL10 (IP-10) (sc-1406, Santa Cruz Biotechnology Inc, California, USA) $(2 \mu \mathrm{g} /$ mL), CCL8 (MCP2) (sc-1307, Santa Cruz Biotechnology Inc, California, USA) $(2 \mu \mathrm{g} / \mathrm{mL})$, CCL4 (MIP1 $\beta$ ) (AF-271-NA, R\&D Systems Inc, USA) $(5 \mu \mathrm{g} / \mathrm{mL})$ and CXCL8 (IL-8) (AF-208-NA, R\&D Systems, Inc, USA) $(2.5 \mu \mathrm{g} / \mathrm{mL})$. For CCL11 (eotaxin) detection, a rat monoclonal antibody (MAB-320, R\&D Systems Inc, USA) (5 $\mu \mathrm{g} / \mathrm{mL}$ ) was used. Mouse monoclonal antibodies against the following human chemokine receptors were purchased from R\&D Systems Inc (Minneapolis, USA) (5 $\mu \mathrm{g} / \mathrm{mL}$ ): CXCR3 (MAB-160), CCR3 (MAB-155), CCR5 (MAB-181) and CCR7 (MAB-197). Biotinylated horse anti-mouse $\operatorname{IgG}$, biotinylated horse anti-goat $\operatorname{IgG}$ or biotinylated rabbit anti-rat secondary antibodies were used at $15 \mu \mathrm{g} / \mathrm{mL}$ (all Vector Laboratories, Burlingame, USA). All antibodies were diluted in PBS.

Immunohistochemistry - For immunohistochemistry, we used a previously described immunostaining procedure (Diaz et al. 2002). Briefly, the samples were hydrated in PBS and sequentially incubated for $60 \mathrm{~min}$ at room temperature with a primary mouse monoclonal antibody or for $120 \mathrm{~min}$ at $37^{\circ} \mathrm{C}$ with a goat polyclonal antibody. Then, the samples were incubated with a biotinylated horse antimouse IgG, a biotinylated horse anti-goat $\mathrm{IgG}$ or a biotinylated rabbit anti-rat IgG diluted 1:100 $(15 \mu \mathrm{g} / \mathrm{mL}$, all from Vector Laboratories, Burlingame, USA) for $30 \mathrm{~min}$. Next, the samples were treated with the Vectastain ${ }^{\mathbb{E}}$ Elite $\mathrm{ABC}$ kit (Vector Laboratories, Burlingame, USA) for 30 min. Incubations were performed in a Shandon Coverplate $^{\text {TM }}$ system (Pittsburgh, USA) and 5-min washes with PBS were performed between steps. Reactions were developed for 3 min with Vector ${ }^{\mathbb{B}}$ NovaRed ${ }^{\mathrm{TM}}$ substrate. The sections were then washed, counterstained with Harris haematoxylin, dehydrated and mounted with DPX (BDH Chemicals Ltd, Pool, England). Omission of the primary antibody served as the control.

Leukocyte quantification - Cells were counted using a light microscope (Leica, Wetzlar, Germany) connected to a colour video monitor that was calibrated to determine the number of cells $/ \mathrm{mm}^{2}$. Only cells with a visible nucleus and red immunostaining were counted as positive. To obtain a representative sample of the lesions, two non-serial alternate sections were immunostained and counted for each cell marker. All of the fields of inter- 
est were counted in each section at a magnification of $400 \mathrm{X}$, resulting in $2-4 \times 10^{4}$ counted cells per section. The percentage of each phenotype was calculated. Previous counts of the nucleated cells in H\&E-stained sections indicated that there were approximately 6,000 cells $/ \mathrm{mm}^{2}$ in the infiltrate of LCL and ICL patients and approximately 4,000 cells $/ \mathrm{mm}^{2}$ in DCL patients.

Statistical analysis - The distribution of the data was analysed with the Kalmogorov-Smirnov normality test. Because not all variables from the leukocyte quantification had a normal distribution and the size of the patient groups was small, the comparison between groups was performed using the nonparametric Mann-Whitney $U$ test. The data are represented as the numbers of positive cells $/ \mathrm{mm}^{2}$ (medians, range and interquartile range) and $\mathrm{p}$ values less than 0.05 were considered significant. Correlations between the variables were analysed using the Spearman rank coefficient. Moreover, clinical data depicting the leishmanin test values and the time of evolution showed a normal distribution and the comparison between groups was therefore performed using an unpaired t test. All tests were performed using GraphPad InStat 3.02 (GraphPad Software, San Diego, California USA) (graphpad.com).

\section{RESULTS}

Three groups of patients with different clinical forms of cutaneous leishmaniasis were studied (LCL, $\mathrm{n}=20$; ICL, $\mathrm{n}=5$; DCL, $\mathrm{n}=10$ ). These patients were diagnosed using established clinical, epidemiological, histopathological and parasitological criteria (Convit et al. 1993).

The clinical examination showed that LCL patients had one or two localised ulcers with infiltrated borders in exposed areas; the mean evolution period was 2.2 months at the time of the first medical consultation. ICL patients were identified according to the presence of single or multiple lesions with verrucous, sarcoidal or vegetative plaques with $6 \pm 2.3$ months of evolution and DCL patients presented with a prolonged natural history (118 \pm 132 months) and multiple disseminated lesions such as papules, plaques and nodules. The leishmanin skin test was strongly positive in LCL $(21.2 \pm 8.3$, mean \pm standard deviation) and ICL patients $(15.3 \pm 4.8)$, whereas DCL patients were negative $(0.7 \pm 2.4)$ (Table). The histological analysis of skin biopsies confirmed the diagnosis of LCL, ICL or DCL, with the variable presence of Leishmania parasites in LCL and ICL patients and large numbers of parasites in DCL patients.

The immunohistological analysis showed a tendency for a higher density of CXCL10-positive cells in the granulomas of patients with LCL (median 250 cells/ $\mathrm{mm}^{2}$, ranging from $0-888$ cells $\left./ \mathrm{mm}^{2}\right)$ and ICL (263, $0-525$ cells $/ \mathrm{mm}^{2}$ ) as compared to DCL patients (138, $0-488$ cells $/ \mathrm{mm}^{2}$ ) (Fig. 1A). All patients with LCL and ICL and $70 \%$ of those with DCL showed CXCL10 expression in the epidermis, sweat glands and nerve fibres (Fig. 2A-C). The analysis of CCL4 and CCL8 expression showed similar results for infiltrating granuloma cells and an augmented density of CCL4- and CCL8-positive cells in patients with LCL (406, 0-1,050 CCL4+ cells/ $\mathrm{mm}^{2}$ and 487, 0-1,238 CCL8+ cells $/ \mathrm{mm}^{2}$, respectively) as compared to DCL $\left(75,0-925 \mathrm{CCL} 4+\right.$ cells $/ \mathrm{mm}^{2}$ and 100, 0-825 CCL8+ cells $/ \mathrm{mm}^{2}$ ) (both $\mathrm{p}<0.05$ ) (Fig. 1A, C). Although no differences were observed regarding CCL11 expression in the infiltrate between groups, $35 \%$ of patients with LCL, $80 \%$ of those with ICL and $50 \%$ of those with DCL exhibited CCL11-positive DCs in the epidermis (Fig. 2G). The density of CCL11-positive epidermal DCs was also higher in ICL (150, 0-225 cells/ $\left.\mathrm{mm}^{2}\right)$ and DCL $\left(38,0-138\right.$ cells $\left./ \mathrm{mm}^{2}\right)$ patients than in LCL patients $\left(0,0-188\right.$ cells $\left./ \mathrm{mm}^{2}, \mathrm{p}<0.05\right)$ (Fig. 1C).

Furthermore, when we evaluated the chemokine receptors expressed on the infiltrating cells in the lesion, we found higher numbers of CXCR3-positive cells in patients with LCL $\left(1,637\right.$, ranging from $425-2,750$ cells $\left./ \mathrm{mm}^{2}\right)$ and ICL $\left(1,722,1,400-2,000\right.$ cells $\left./ \mathrm{mm}^{2}\right)$ as compared to those with DCL $\left(950,125-1,313\right.$ cells $\left./ \mathrm{mm}^{2}, \mathrm{p}<0.05\right)$ (Fig. $1 \mathrm{~B})$, indicating a positive correlation with the expression of its ligand CXCL10 $(r=0.3984 ; p=0.0239)$. Although these differences were not significant, we observed a tendency for an increased density of CCR5-positive cells in LCL patients $\left(575,0-1,763\right.$ cells $\left./ \mathrm{mm}^{2}\right)$ compared to DCL patients $\left(238,0-1,163\right.$ cells $\left./ \mathrm{mm}^{2}\right)$ (Fig. 1B). However, no correlation between CCR5 and its ligand CCL4 was observed. Moreover, no significant differences were observed regarding the density of CCR3+ cells in the different clinical forms of leishmaniasis evaluated (LCL, 500, $0-1,765$ cells $/ \mathrm{mm}^{2}$; ICL, 638, 0-1,025 cells $/ \mathrm{mm}^{2}$; DCL, $307,0-11,253$ cells $/ \mathrm{mm}^{2}$ ) (Fig. 1D) and CCR3 expression was not correlated with that of its ligand CCL11.

In addition, we evaluated CXCL8 expression, which plays a role in the recruitment of PMN cells. The expression of this chemokine was not significantly different between the groups of patients evaluated (Fig. 1E). However, we found clear differences in CCR7 expression in granuloma cells from patients with different clinical forms; lesions from patients with LCL showed a higher density of CCR7-positive cells $\left(887,288-1,763\right.$ cells $\left./ \mathrm{mm}^{2}\right)$ as compared to patients with ICL $\left(173,0-775\right.$ cells $/ \mathrm{mm}^{2}, \mathrm{p}$ $<0.05)$ or DCL $\left(536,100-1,300\right.$ cells $\left./ \mathrm{mm}^{2}, \mathrm{p}<0.05\right)$ (Fig. $1 \mathrm{~F})$. In addition, $30 \%$ of patients with LCL and $20 \%$ of patients with ICL, but none of the DCL patients, showed CCR7-positive epidermal DCs (Figs 1F, 2I).

TABLE

Clinical characteristics of different groups of patients

\begin{tabular}{lccc}
\hline Diagnostic & $\begin{array}{c}\text { Age } \\
(\text { mean } \pm \text { SD) }\end{array}$ & $\begin{array}{c}\text { Leishmanin } \\
(\mathrm{mm})\end{array}$ & $\begin{array}{c}\text { Time of evolution } \\
(\text { months }\end{array}$ \\
\hline LCL $(\mathrm{n}=20)$ & $34 \pm 16$ & $21.2 \pm 8.3^{a}$ & $2.2 \pm 1.8^{a}$ \\
ICL $(\mathrm{n}=5)$ & $36 \pm 20$ & $15.3 \pm 4.8^{a}$ & $6 \pm 2.3^{a}$ \\
DCL $(\mathrm{n}=10)$ & $17 \pm 13$ & $0.7 \pm 2.4$ & $118 \pm 132$ \\
\hline
\end{tabular}

$a: \mathrm{p} \leq 0.05$ compared with diffuse cutaneous leishmaniasis (DCL); ICL: intermediate cutaneous leishmaniasis; LCL: localised cutaneous leishmaniasis; SD: standard deviation. 


\section{DISCUSSION}

Chemokines play an important role during innate and adaptive immunity in cutaneous leishmaniasis. It is known that macrophages produce CCL4, an inflammatory chemokine that recruits CD4+ lymphocytes (Schall et al. 1993) and is increased in the serum of patients with cutaneous leishmaniasis (Vargas-Inchaustegui et al. 2010). In lesions, we observed elevated levels of CCL4 and CCL8 in LCL patients and these chemokines contribute to the recruitment of macrophages and DCs activated by CCL2 in synergy with IFN- $\gamma$ (Ritter et al. 1996, Jimenez et al. 2010). In contrast, the expression of CXCL8 was similar in LCL, ICL and DCL patients. It has been demonstrated that human monocytes infected with Leishmania major demonstrate chemotactic activity for neutrophils and monocytes due to CXCL8 production (Badolato et al. 1996). Moreover, contact with Leishmania induces the release of CXCL8 by PMNs (van Zandbergen et al. 2002), which indicates a potential role for neutrophils in the pathogenesis of active forms of leishmaniasis, as previously demonstrated by Boaventura et al. (2010) in mucosal leishmaniasis associated with a Th17 response.

Immature DCs are able to internalise parasites and migrate to the regional lymph node for antigen presentation. This migratory ability depends on the expression of CCR7, the receptor for CCL21 and CCL19 produced in secondary lymphoid tissues (Förster et al. 1999). These results suggest that patients with LCL have improved migration of DCs to lymph nodes. In addition, epidermal DCs may be activated to migrate in a CCR7dependent manner in patients with LCL and ICL but not DCL and this may contribute to the development of a more efficient adaptive response against the parasite in LCL than in other active clinical forms of the disease. It has also been demonstrated that reduced expression of CCR7 and defective DC migration play a major role in the pathogenesis of visceral leishmaniasis in mice (Ato et al. 2002, 2006). Furthermore, the expression level of
A

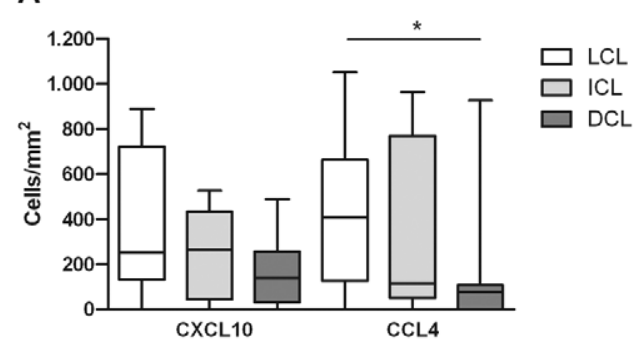

C

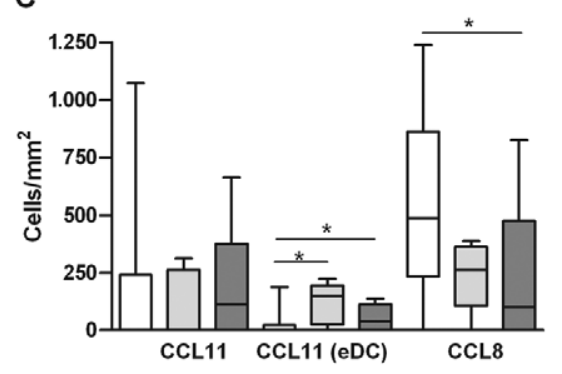

E

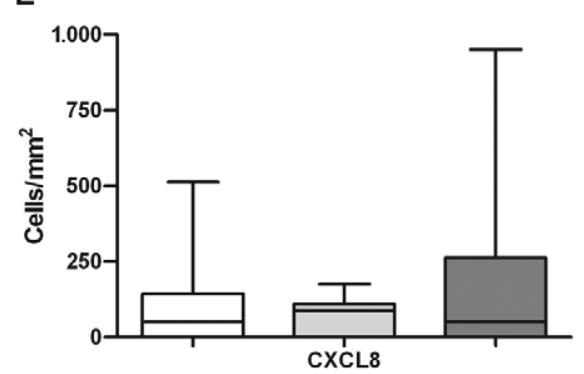

B

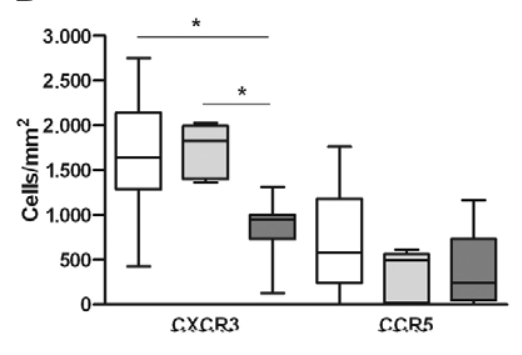

D

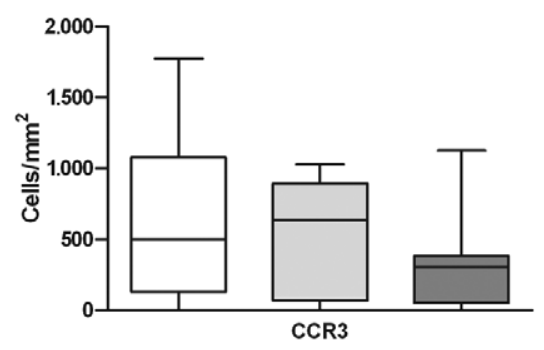

$\mathbf{F}$

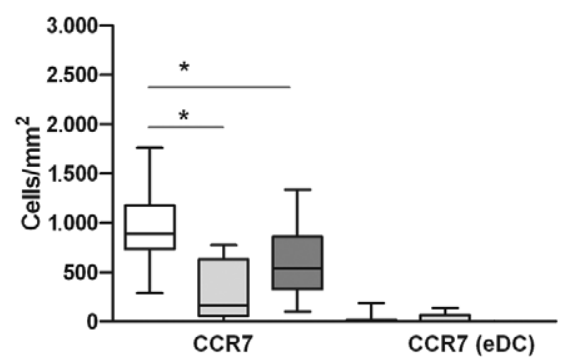

Fig. 1: chemokines and chemokine receptors in lesions of different clinical forms of American cutaneous leishmaniasis. A, B: density of CXCL10, CCL4, CXCR3 and CCR5 positive cells; C, D: density of CCL11, CCL8 and CCR3 positive cells; E: density of CXCL8; F: CCR7 positive cells. Data are represented as medians and interquartile range patients with localised cutaneous leishmaniasis $(\mathrm{LCL})(\mathrm{n}=20)$, intermediate cutaneous leishmaniasis (ICL) $(n=5)$ and diffuse cutaneous leishmaniasis $(\mathrm{DCL})(\mathrm{n}=10)$. Asterisk means $\mathrm{p}<0.05$ comparing LCL with DCL, LCL with ICL and LCL with ICL by the Mann-Witney $U$ test. 
CCR7 and the DC response to the CCR7 ligand CCL21 was shown to be increased after contact with $L$. major in both resistant and susceptible mice (Steigerwald \& Moll 2005). Thus, it is possible that the modulation of chemokine receptor expression on DCs depends upon the infecting Leishmania species.

The chemokines produced at the site of infection are critical for determining the composition of the infiltrating cells. In the lesions of LCL and ICL patients, elevated levels of CXCL10 are produced by the epidermis and stromal cells in the dermis, which attracts CXCR $3+$ cells, including Th1 cells (Sebastiani et al. 2001) and the majority of the infiltrating cells in LCL and ICL lesions (Convit et al. 1993). These data confirm our previous result indicating that a Th1 response occurs in LCL, whereas a mixed Th1/Th2 response occurs in patients with ICL (Diaz et al. 2002). Our results also coincide with those obtained by Geiger et al. (2010), who concluded that CXCR3+ Th1 lymphocytes are important for the resolution of cutaneous lesions in leishmaniasis. Furthermore, LCL patients with a high density of CXCR3+ cells respond well to treatment and may resolve lesions spontaneously, whereas ICL patients develop more severe and persistent lesions following primary infection. Thus, it is possible

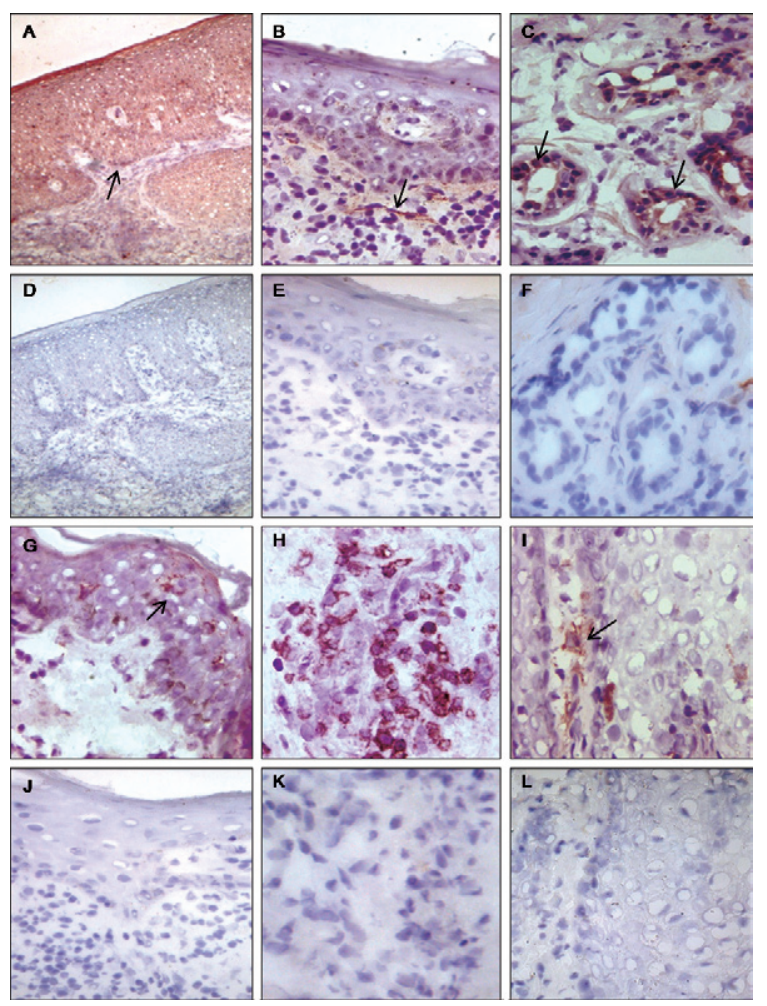

Fig. 2: immunolabelling of chemokine in lesions American cutaneous leishmaniasis. Detection of CXCL10 on the epidermal cells (A), nerve fibres (B) and glands (C) of a patient with localised cutaneous leishmaniasis (LCL) with their respective negative controls (D, E, F). Epidermal CCL11+ dendritic cells (D) in a patient with diffuse cutaneous leishmaniasis (DCL). Infiltrating CCR3+ cells (E) in a patient with DCL. CCR7+ cells in a patient with LCL (F). Respective negative controls (J-L). Original magnification: 400X and 200X (A, D). that patients with ICL and other relapsed forms of leishmaniasis mount a specific type of immune response. In addition, recent evidence demonstrates the involvement of a Th17 response in the pathogenesis of cutaneous, mucosal and post-kala-azar dermal leishmaniasis (Bacellar et al. 2009, Lopez Kostka et al. 2009, Boaventura et al. 2010, Katara et al. 2012).

Following early natural killer cell stimulation by IFN- $\gamma$, resident cells release elevated levels of CXCL10. Subsequently, CXCR3+ Th1 cells are recruited and more IFN- $\gamma$ is released and keratinocytes are stimulated to produce more CXCL10 and CCL2 (Albanesi et al. 2001). In LCL and ICL patients, this continuous feedback loop leads to the elimination of most parasites by activated macrophages. However, the exacerbated immune response in ICL lesions leads to extensive tissue damage and this exacerbated immune response is likely due to failures in the regulation of the T cell response. For example, Rodriguez-Pinto et al. (2012) demonstrated that CD4+CD25+ cells from asymptomatic individuals had a higher capacity to suppress IFN- $\gamma$ production by CD4+ effector T cells than those from patients with chronic cutaneous leishmaniasis.

An association between CCL11 and the Th2 response in allergic dermatitis has been demonstrated (Yawalkar et al. 1999), as well as the expression of its receptor CCR3 on a subset of Th2 cells (Sebastiani et al. 2001). In the present study, no significant differences in CCL11 or CCR3 expression were observed between groups of patients and this result agrees with recent work showing a similar expression pattern for CCL11 in patients with LCL and disseminated leishmaniasis in Brazil (Machado et al. 2011). However, we observed in LCL lesions that CXCL10+ cells were twice as abundant as CCL11+ cells, whereas DCL lesions expressed similar levels of both chemokines. Furthermore, CCL11 is expressed on epidermal DCs in ICL and DCL patients, suggesting a role for these cells in the recruitment of CCR $3+$ cells in these patients.

This study detected expression of the chemokines CCL11 and CXCL10 in epidermal cells, suggesting the participation of the epithelium in the immune response against Leishmania. In support of this notion, growing evidence has demonstrated that chemokines released from epidermal cells control inflammatory skin diseases. Keratinocytes secrete both Th1 and Th2-associated chemokines, although the former type is more abundantly produced than the latter. In fact, decreasing keratinocyte production of chemokines is one of the therapeutic approaches to treat cutaneous inflammatory disorders (Tokura et al. 2008).

In conclusion, for a protective immune response against Leishmania, the recruitment of appropriate leukocyte subpopulations resulting from the expression of chemokines and chemokine recognition by the appropriate receptors is essential. Our data suggest that the immune response in the lesions of LCL patients is associated with a CXCL10-dominated pattern of chemokine expression, which serves to attract CXCR3+ Th1 cells and promote efficient DC migration to lymph nodes via CCR7 expression. In contrast, DCL patients show low expression levels of chemokines associated with a Th1 
response and instead express CCL11 in epidermal DCs, which contributes to the recruitment of CCR3+ cells. In both of these immune processes, the epidermis plays an important role as the inducer of the immune response via chemokine production by keratinocytes and epidermal DCs, which can be activated and migrate to lymph nodes in LCL patients, but not in DCL patients.

\section{ACKNOWLEDGEMENTS}

To the patients who participated in this study.

\section{REFERENCES}

Albanesi C, Scarponi C, Sebastiani S, Cavani A, Federici M, Sozzani S, Girolomoni GA 2001. Cytokine-to-chemokine axis between T lymphocytes and keratinocytes can favor Th1 cell accumulation in chronic inflammatory skin diseases. J Leukoc Biol 70: 617-623.

Ato M, Maroof A, Zubairi S, Nakano H, Kakiuchi T, Kaye PM 2006. Loss of dendritic cell migration and impaired resistance to Leishmania donovani infection in mice deficient in CCL19 and CCL21. J Immunol 176: 5486-5493.

Ato M, Stager S, Engwerda CR, Kaye PM 2002. Defective CCR7 expression on dendritic cells contributes to the development of visceral leishmaniasis. Nat Immunol 12: 1185-1191.

Bacellar O, Faria D, Nascimento M, Cardoso TM, Gollob KJ, Dutra WO, Scott P, Carvalho EM 2009. Interleukin 17 production among patients with American cutaneous leishmaniasis. J Infect Dis 200: 75-78.

Badolato R, Sacks DL, Savoia D, Musso T 1996. Leishmania major: infection of human monocytes induces expression of IL-8 and MCAF. Exp Parasitol 82: 21-26.

Boaventura VS, Santos CS, Cardoso CR, de Andrade J, dos Santos WL, Clarêncio J, Silva JS, Borges VM, Barral-Netto M, Brodskyn CI, Barral A 2010. Human mucosal leishmaniasis: neutrophils infiltrate areas of tissue damage that express high levels of Th17-related cytokines. Eur J Immunol 40: 2830-2836.

Bonecchi R, Bianchi G, Bordignon PP, D’Ambrosio D, Lang R, Borsatti A, Sozzani S, Allavena P, Gray PA, Mantovani A, Sinigaglia F 1998. Differential expression of chemokine receptors and chemotactic responsiveness of type $1 \mathrm{~T}$ helper cells (Th1s) and Th2s. J Exp Med 187: 129-132.

Caceres-Dittmar G, Tapia FJ, Sanchez MA, Yamamura M, Uyemura K, Modlin RL, Bloom BR, Convit J 1993. Determination of the cytokine profile in American cutaneous leishmaniasis using the polymerase chain reaction. Clin Exp Immunol 91: 500-505.

Campanelli AP, Brodskyn CI, Boaventura V, Silva C, Roselino AM, Costa J, Saldanha AC, de Freitas LA, de Oliveira CI, Barral-Netto M, Silva JS, Barral A 2010. Chemokines and chemokine receptors coordinate the inflammatory immune response in human cutaneous leishmaniasis. Hum Immunol 71: 1221-1227.

Convit J, Ulrich M, Fernandez CT, Tapia FJ, Caceres-Dittmar G, Castes M, Rondon AJ 1993. The clinical and immunological spectrum of American cutaneous leishmaniasis. Trans $R$ Soc Trop Med Hyg 87: 444-448.

Diaz NL, Zerpa O, Ponce LV, Convit J, Rondon AJ, Tapia FJ 2002. Intermediate or chronic cutaneous leishmaniasis: leukocyte immunophenotypes and cytokine characterisation of the lesion. Exp Dermatol 11: 34-41.

Farber JM 1997. Mig and IP-10: CXC chemokines that target lymphocytes. J Leukoc Biol 61: 246-257.

Förster R, Schubel A, Breitfeld D, Kremmer E, Renner-Muller I, Wolf E, Lipp M 1999. CCR7 coordinates the primary immune response by establishing functional microenvironments in secondary lymphoid organs. Cell 99: 23-33.

Geiger B, Wenzel J, Hantschke M, Haase I, Ständer S, von Stebut E 2010. Resolving lesions in human cutaneous leishmaniasis predominantly harbour chemokine receptor CXCR3-positive T helper 1/T cytotoxic type 1 cells. Br J Dermatol 162: 870-874.

Jimenez F, Quinones MP, Martinez HG, Estrada CA, Clark K, Garavito E, Ibarra J, Melby PC, Ahuja SS 2010. CCR2 plays a critical role in dendritic cell maturation: possible role of CCL2 and NFkappa B. J Immunol 184: 5571-5581.

Katara GK, Ansari NA, Singh A, Ramesh V, Salotra P 2012. Evidence for involvement of Th17 type responses in post kalaazar dermal leishmaniasis (PKDL). PLoS Negl Trop Dis 6: e1703.

Kim CH, Rott L, Kunkel EJ, Genovese MC, Andrew DP, Wu L, Butcher EC 2001. Rules of chemokine receptor association with T cell polarization in vivo. J Clin Invest 108: 1331-1339.

Laudanna C, Kim JY, Constantin G, Butcher E 2002. Rapid leukocyte integrin activation by chemokines. Immunol Rev 186: 37-46.

Lopez Kostka S, Dinges S, Griewank K, Iwakura Y, Udey MC, von Stebut E 2009. IL-17 promotes progression of cutaneous leishmaniasis in susceptible mice. J Immunol 182: 3039-3046.

Machado PR, Rosa ME, Costa D, Mignac M, Silva JS, Schriefer A, Teixeira MM, Bacellar O, Carvalho EM 2011. Reappraisal of the immunopathogenesis of disseminated leishmaniasis: in situ and systemic immune response. Trans R Soc Trop Med Hyg 105: 438-444.

Ohmori Y, Wyner L, Narumi S, Armstrong D, Stoler M, Hamilton TA 1993. Tumor necrosis factor-alpha induces cell type and tissuespecific expression of chemoattractant cytokines in vivo. $\mathrm{Am} \mathrm{J}$ Pathol 142: 861-870.

Peters NC, Egen JG, Secundino N, Debrabant A, Kimblin N, Kamhawi S, Lawyer P, Fay MP, Germain RN, Sacks D 2008. In vivo imaging reveals an essential role for neutrophils in leishmaniasis transmitted by sandflies. Science 321: 970-974.

Ritter U, Körner H 2002. Divergent expression of inflammatory dermal chemokines in cutaneous leishmaniasis. Parasite Immunol 24: 295-301.

Ritter U, Moll H, Laskay T, Brocker E, Velazco O, Becker I, Gillitzer R 1996. Differential expression of chemokines in patients with localized and diffuse cutaneous American leishmaniasis. $J$ Infect Dis 173: 699-709.

Rodriguez-Pinto D, Navas A, Blanco VM, Ramírez L, Garcerant D, Cruz A, Craft N, Saravia NG 2012. Regulatory T cells in the pathogenesis and healing of chronic human dermal leishmaniasis caused by Leishmania (Viannia) species. PLoS Negl Trop Dis 6: e1627.

Schall TJ, Bacon K, Camp RD, Kaspari JW, Goeddel DV 1993. Human macrophage inflammatory protein alpha (MIP-1 alpha) and MIP-1 beta chemokines attract distinct populations of lymphocytes. $J$ Exp Med 177: 1821-1826.

Sebastiani S, Allavena P, Albanesi C, Nasorri F, Bianchi G, Traidl C, Sozzani S, Girolomoni G, Cavani A 2001. Chemokine receptor expression and function in $\mathrm{CD} 4^{+} \mathrm{T}$ lymphocytes with regulatory activity. J Immunol 166: 996-1002.

Silva F, Gomes R, Prates D, Miranda JC, Andrade B, Barral-Netto M, Barral A 2005. Inflammatory cell infiltration and high antibody production in BALB/c mice caused by natural exposure to Lutzomyia longipalpis bites. Am J Trop Med Hyg 72: 94-98.

Steigerwald M, Moll H 2005. Leishmania major modulates chemokine and chemokine receptor expression by dendritic cells and affects their migratory capacity. Infect Immun 73: 2564-2567.

Teixeira MJ, Teixeira CR, Andrade BB, Barral-Netto M, Barral A 2006. Chemokines in host-parasite interactions in leishmaniasis. Trends Parasitol 22: 32-40. 
Tokura Y, Kobayashi M, Kabashima K 2008. Epidermal chemokines and modulation by antihistamines, antibiotics and antifungals. Exp Dermatol 17: 81-90.

van Zandbergen G, Hermann N, Laufs H, Solbach W, Laskay T 2002. Leishmania promastigotes release a granulocyte chemotactic factor and induce interleukin- 8 release, but inhibit gamma interferon-inducible protein 10 production by neutrophil granulocytes. Infect Immun 70: 4177-4184.

van Zandbergen G, Klinger M, Mueller A, Dannenberg S, Gebert A, Solbach W, Laskay T 2004. Cutting edge: neutrophil granulocyte serves as a vector for Leishmania entry into macrophages. J Immunol 173: 6521-6525.
Vargas-Inchaustegui DA, Hogg AE, Tulliano G, Llanos-Cuentas A, Arevalo J, Endsley JJ, Soong L 2010. CXCL10 production by human monocytes in response to Leishmania braziliensis infection. Infect Immun 78: 301-308.

Williams JR 2008. The Declaration of Helsinki and public health. Bull World Health Organ 86: 650-652.

Yawalkar N, Uguccioni M, Scharer J, Braunwalder J, Karlen S, Dewald B, Braathen LR, Baggiolini M 1999. Enhanced expression of eotaxin and CCR3 in atopic dermatitis. J Invest Dermatol 113: 43-48.

Zaph C, Scott P 2003. Interleukin-12 regulates chemokine gene expression during the early immune response to Leishmania major. Infect Immun 71: 1587-1589. 